\title{
Cumulative effects of land use on fish metrics in different types of running waters in Austria
}

\author{
Clemens Trautwein $\cdot$ Rafaela Schinegger • \\ Stefan Schmutz
}

Received: 16 December 2010/Accepted: 7 July 2011/Published online: 5 August 2011

(C) The Author(s) 2011. This article is published with open access at Springerlink.com

\begin{abstract}
The catchment land-use composition of 249 fish sampling sites in Austrian running waters revealed effects on the biological integrity. Beyond correlative analysis, we investigated (1) which land-use category had the strongest effect on fish, (2) whether metrics of functional fish guilds reacted differently, (3) whether there were cumulative effects of land-use categories, and (4) whether effects varied in strength across river types. We fed 5 landuse categories into regression trees to predict the European Fish Index or fish metric of intolerant species (mainly Salmo trutta fario). Agriculture and urbanisation were the best predictors and indicated significant effects at levels of $>23.3$ and $>2 \%$, respectively. Model performance was $R^{2}=0.15$ with the Fish Index and $R^{2}=0.46$ with intolerant species. The tree structure showed a cumulative effect from agriculture and urbanisation. For the intolerant species metric, a combination of high percentages for agriculture and urbanisation was related to moderate status, whereas $<7.3 \%$ agriculture were related to good status, although urbanisation was higher than $1.8 \%$. Headwater river types showed stronger responses to land use than river types of lower gradient and turned out to be more sensitive to urbanisation than agriculture.
\end{abstract}

Keywords Land use - Fish - Cumulative effect . Stream integrity · Fish metrics - IBI - Moran's I · Landscape composition

C. Trautwein $(\varangle) \cdot$ R. Schinegger $\cdot$ S. Schmutz Department of Water, Atmosphere and Environment, Institute of Hydrobiology and Aquatic Ecosystem Management, BOKU, University of Natural Resources and Life Sciences, Max Emanuel-Strasse 17, 1180 Vienna, Austria

e-mail: clemens.trautwein@boku.ac.at

URL: http://www.wau.boku.ac.at/ihg.html

\author{
Abbreviations \\ EFT European fish type \\ CLC CORINE land cover \\ CRT Classification and regression trees \\ IBI Index of biotic integrity \\ MI Moran's I index
}

\section{Introduction}

Land use and stream response

Rivers in the context of their catchments-also called riverscapes-are considered to be ecosystems that are strongly affected by human actions in the landscape (Allan 2004b). The guiding principle of much riverine research at the landscape-scale is that human actions impact the composition and function of aquatic organisms, e.g., fish. Human alterations and impacts that directly affect the physico-chemical conditions of running waters and strongly influence the aquatic biota are referred to as pressures in this study. Many, although not all, impacts on streams are entirely or partly linked to human activities in the landscape and thus can be quantified from data on land use (Allan 2004a). A useful way to measure land use is to assess landscape composition at the class level (Botequilha Leitao et al. 2006).

A (higher) proportion of agriculture has been shown to have detrimental effects on biota (Allan 2004b; Allan et al. 1997; Richards et al. 1996; Roth et al. 1996). Urbanisation, impervious land cover and roads frequently have significant impacts on rivers. The upstream drainage area for fish sampling locations-referred to as catchment area-is commonly understood as an important scale of 
investigation. Even relatively small amounts of urbanised areas within a stream catchment, e.g., $<5 \%$, have adverse effects on stream integrity. Non-linearity in the relationship between urbanisation and stream condition has been reported by Gergel et al. (2002) and Miltner et al. (2004). Linkages are related to altered hydrology (e.g., increased peak surface runoff), altered sediment delivery patterns, intrusion of pollutants and toxins, and habitat degradation (Beechie et al. 2010).

Fish react to both chemical and physical water quality and hydro-morphological conditions; therefore, fish are an ideal indicator for multiple-impacted rivers (EC of European Parliament 2000, WFD). Fish are present in most surface waters, they occupy a wide variety of riverine habitats, are relatively easy to identify, and their taxonomy and ecological requirements are well studied. Because of their migration patterns and longevity, fish communities reflect aquatic conditions over relatively large spatial and long time scales (Pont et al. 2006).

Integrative measures of river condition, such as Indices of Biotic Integrity (IBIs), are particularly useful for assessing overall stream health because they integrate multiple influences. IBIs are multi-metric indices based on structural (taxonomic) and functional (species guilds and traits) metrics (Karr 1981). However, Allan (2004a) argues that multi-metric bioassessment methods may fail in diagnosing causes of degradation because these indices are constructed with the intention to reflect multiple stressors. This calls for testing single metrics of species traits, feeding and reproductive guilds, taxa of known tolerance to particular stressors, and other less-aggregated measures for evaluating pathways and mechanisms between landscapes, instream habitats and fish IBIs (Poff 1997).

Most studies have identified landscape effects for single land-use categories only. Agriculture and urbanisation are well-studied human impacts. Nonetheless, the interaction effects and cumulative effects from multiple land-use categories are poorly understood. This can be attributed to the use of (multiple) linear regression analysis. Because of the multitude of ecological variables in landscape studies, only the main effects were considered, whereas interaction effects were not included. New and innovative statistical methods are needed to obtain results that better interpret interactions, cumulative effects and threshold values.

Numerous studies have dealt with few sampling sites and focused on streams dominated by either agricultural (Stewart et al. 2001; Roth et al. 1996) or urban land use (Wang et al. 2001, 2003). Larger datasets covering many different river types can be used to analyse effects of multiple land use and differences in response between river types.

Relationships and processes are considered to have different influences within river typologies. The Ecoregion concept of Illies and Andrássy (1978) or Omernik and Bailey (1997) delineates both geographically and ecologically homogeneous areas. Huet (1949) conceptualised fish zones for running waters mainly based on river slope. Fish zones account for the natural variability of fish communities along the longitudinal gradient of rivers. They imply that typical assemblages, e.g., brown trout dominated communities (S. trutta L.), occur throughout the many ecoregions all over Europe. Considering these two concepts, Melcher et al. (2007) identified assemblage types for European fish fauna and developed a predictive model using abiotic characteristics. Thus, the model of Melcher covers the aspects of regionalism and longitudinal river zonation. Steel et al. (2010) also proposed to examine landscape-fish relationships across disparate catchments, ecoregions and ecosystems to test whether there are, in fact, generalisable effects. However, using a heterogeneous dataset in terms of spatial distribution and river size requires considering the underlying abiotic and biotic characteristics, which can lead to spurious effects in the results.

We hypothesise that different fish assemblages respond differently to land uses. Upper tributaries that mainly host assemblages with low species numbers may be less vulnerable to land-use impacts compared to assemblages of medium to large rivers. This is due to the importance of lateral connectivity and the exchange of nutrients, organic and inorganic materials, which increases with river size (Ward 1989).

The present study was designed to identify empirical relationships between human land use and the biotic integrity of rivers and streams. Besides using a general fish index as a measure of ecological status, we also focus on fish metrics of certain ecological functional groups (trophic and reproduction guilds). These metrics of fish species with special feeding and reproductive behaviour may help to interpret linkages between landscape-scale human actions and in-stream biotic responses.

Research questions addressed within this study were (1) is there a relationship between the composition of land use and fish assemblages, and which land-use category has the strongest effect on fish, (2) do metrics of functional fish guilds respond differently to land use, and which guilds were most strongly affected by land use, (3) can we identify a cumulative effect for several land-use categories showing a stronger impact than single land-use categories and quantify thresholds, and (4) do land use effects vary in strength across different Austrian river types?

\section{Methods and data}

To characterise landscapes, we calculated the landscape composition (percentage of six different land-use 
categories) within a catchment area for individual fish sampling sites. Our scale of investigation was the catchment scale because this has been the most influential scale in several studies of landscape-river research (Allan 2004b; Allan and Johnson 1997; Roth et al. 1996). It also showed a higher relative effect for impacted sites than local or reach scales (Wang et al. 2006b), which were reported to be subject to a hierarchy of controls from large to small spatial extents (Durance et al. 2006).

Land cover data, delineated European watersheds and river networks were processed with GIS software (ArcGIS Desktop 9.3, ESRI (C) 1999-2008).

We used the CORINE land cover data 2000 (CLC2000; European Environmental Agency; www.eea.europa.eu/) for landscape characterisation. The CCM River and Catchment database, version 2.0 (CCM2) (Vogt et al. 2007) was used to determine the catchments associated with each sampling point. That is, each sampling point was assigned to distinct hydrologic primary catchments (surface area draining into confluent to confluent river segment). The tool 'thematic raster summary' (Beyer 2004) performed a spatial overlay of land cover data to evaluate the absolute area of each land-cover/land-use (hereafter land-use) category within primary catchments. The hydrologic coding of CCM allowed tracking of all upstream primary catchments along the upstream drainage network. The hydrologically coded database structure was used to aggregate absolute values of land-use variables within the whole upstream catchment area. Finally, land-use composition is the ratio between the area of each land-use category and catchment size. Accordingly, 0.40 agriculture means that $40 \%$ of the catchment is occupied by agricultural use.

We evaluated the amounts of six land-use categories in a slightly modified level three definition of CLC2000 code (official CLC three-digit code in brackets in Table 1): agriculture, pasture, urban land, forest, shrubland, and nonvegetated areas. Table 1 provides details on the organisation of the land-use variables. Non-vegetated areas were excluded from further analysis because of their scarce occurrence $($ median $=0$, standard deviation $=0.0969$ ).

Data from single-pass electric fishing by wading and boating according to standards of the CEN norm EN 14011 (CEN 2003) provided the basis for the biotic variables in this study. The fish were identified to species level, their length and weight recorded, and then released back to the stream.

Table 1 Variable description in this study with abbreviations, minima and maxima, and levels of measurement

\begin{tabular}{|c|c|c|c|c|}
\hline Abbrev. & $\begin{array}{l}\text { Minimum/ } \\
\text { maximum }\end{array}$ & $\begin{array}{l}\text { Measurement } \\
\text { scale }\end{array}$ & $\begin{array}{l}\text { Mean/ } \\
\text { median }\end{array}$ & Description (official CORINE code in italics) \\
\hline \multicolumn{5}{|c|}{ Land-use categories } \\
\hline urban_du & $0.00 / 0.34$ & Ratio & $0.02 / 0.02$ & $\begin{array}{l}\text { Urban and artificial surfaces }(111,112,121,122,123,124, \\
131,132,133,141,142)\end{array}$ \\
\hline agri_du & $0.00 / 0.82$ & Ratio & $0.17 / 0.04$ & $\begin{array}{l}\text { Arable land/permanent crops }(211,212,213,221,222,223 \text {, } \\
241,242,243,244)\end{array}$ \\
\hline past_du & $0.00 / 0.60$ & Ratio & $0.10 / 0.08$ & Extensively used grass lands/grazing (231) \\
\hline fores_du & $0.13 / 0.97$ & Ratio & $0.54 / 0.50$ & Broad-leaved/coniferous/mixed forest $(311,312,313)$ \\
\hline scrub_du & $0.00 / 0.48$ & Ratio & $0.11 / 0.01$ & $\begin{array}{l}\text { National grassland/heathland/herbaceous vegetation }(321,322 \text {, } \\
323,324)\end{array}$ \\
\hline noveg_du & $0.00 / 0.51$ & Ratio & $0.05 / 0.00$ & Bare rock/sparsely vegetated/glacier $(331,332,333,334,335)$ \\
\hline \multicolumn{4}{|c|}{ Fish metrics and index } & Description \\
\hline p_inse & $0.00 / 0.98$ & Ratio & $0.61 / 0.66$ & Density of species feeding on insects [ $\mathrm{n} \_$inse $\left.\times \mathrm{ha}^{-1}\right]$ \\
\hline p_omni & $0.00 / 0.98$ & Ratio & $0.51 / 0.57$ & Density of omnivorous species [n_omni $\times \mathrm{ha}^{-1}$ ] \\
\hline p_phyt & $0.00 / 0.99$ & Ratio & $0.58 / 0.61$ & Density of species phytophilic reproduction $\left[\mathrm{n} \_\right.$phyt $\left.\times \mathrm{ha}^{-1}\right]$ \\
\hline p_bent & $0.00 / 0.99$ & Ratio & $0.53 / 0.59$ & \# of benthic species $[n]$ \\
\hline p_rheo & $0.00 / 0.99$ & Ratio & $0.53 / 0.54$ & \# of rheophilic species for habitat $[n]$ \\
\hline p_long & $0.08 / 0.99$ & Ratio & $0.43 / 0.42$ & \# of species migrating over long distances $[n]$ \\
\hline p_pota & $0.00 / 0.99$ & Ratio & $0.49 / 0.52$ & \# of potamodromous species $[n]$ \\
\hline p_lith & $0.00 / 1.0$ & Ratio & $0.67 /-0.67$ & Rel. abundance of lithophilic species [n_lith $\times$ n_total ${ }^{-1}$ ] \\
\hline p_into & $0.01 / 0.99$ & Ratio & $0.55 /-0.55$ & $\begin{array}{l}\text { Rel. \# of generally intolerant species } \\
\quad\left[\mathrm{n} \_s p \_ \text {into } \times \mathrm{n} \_s p \_t^{-1} \mathrm{l}^{-1}\right]\end{array}$ \\
\hline p_tole & $0.00 / 0.94$ & Ratio & $0.56 / 0.62$ & Rel. \# of generally tolerant species [n_sp_into $\times \mathrm{n} \_s p \_t t^{\prime}{ }^{-1}$ ] \\
\hline EFI & $0.07 / 0.80$ & Ratio & $0.55 / 0.55$ & European Fish Index scores \\
\hline EFI_cl & High; ... & Ordinal & & European Fish Index as ecological status class \\
\hline EFT & $\mathrm{A}, \mathrm{B}, \mathrm{C} .$. & Nominal & & European Fish Type \\
\hline
\end{tabular}


Ecological status was assessed according to Pont et al. (2007) with the readily available software tool for the European Fish Index (EFI, http://fame.boku.ac.at/). This tool derives theoretical fish metric values for individual sites based on a predictive model of reference conditions. The larger the difference between predicted and observed conditions of the fish fauna, the worse the ecological status. Input variables needed for reference modelling are environmental variables describing the sampling site: altitude, lakes upstream, distance from source, flow regime, wetted width, geology, air temperature, river slope, and catchment size (Pont et al. 2007).

Finally, the mean of 10 fish metrics (see Table 1) based on species richness and densities make up the European Fish Index. They represent five ecological functional groups: (1) trophic structure (insectivorous and omnivorous species), (2) reproduction strategy (phytophilic and lithophilic sp.), (3) physical habitat preference (benthic and rheophilic sp.), (4) migratory behaviour (long-distance migrating and potamodromous sp.), and (5) tolerance to disturbance (intolerant and tolerant sp.) (Pont et al. 2007; Noble et al. 2007).

Seven of these 10 fish metrics decrease in response to human pressures, whereas three tend to increase with such pressure; the latter are the density of omnivorous and phytophilic species and relative number of tolerant species. For consistency Pont et al. (2007) transformed residuals into the probability of being a reference site. Accordingly, fish metrics and the European Fish Index range from 0 to 1 . EFI scores are assigned to five ecological status classes $(>0.669$ $=$ high; $0.449-0.669$ = good; $0.0279-0.449=$ moderate; $0.187-0.279=$ poor; $<0.187=$ bad $)$.

A simplified European fish assemblage typology (Melcher et al. 2007) served as a grouping variable in the later analysis to determine special relationships between land use and fish.

Melcher et al. (2007) identified 15 homogeneous fish assemblage types in 11 ecoregions and described six main European Fish Types (EFT). These groups represent river types of (A) headwaters with low species richness dominated by brown trout (S. trutta fario), (B) sections with a low gradient dominated by common minnow (Phoxinus phoxinus), (C) assemblages dominated by Thymallus thymallus, known as the greyling zone, (D) rivers dominated by anadromous and potamodromous salmonids, i.e., Salmo salar, S. trutta lacustris, S. trutta trutta, (E) southern fish assemblages including Mediterranean endemics, and (F) lowland rivers. We used the EFT calculation tool included in the EFI software package to predict EFT based on seven environmental descriptors for each sampling site (http://fame.boku.ac.at). Melcher et al. (2007) used discriminate functions for altitude, distance from source, wetted width, river slope, mean annual air temperature, longitude, and latitude to predict EFT. Four EFTs occurred in the Austrian dataset of the present study (see Fig. 1).

\section{Statistical methods}

In order to overcome spatially nested sampling sites producing autocorrelation, the dataset was reduced from 634 to 249 sites in 30 subcatchments in Austria. Reduction was carried out within subcatchments by selecting dispersed samples. Distances between samples were measured along the stream network and Moran's I correlograms were computed for each subcatchment with the software SAM v4.0 (Rangel et al. 2010). Moran's I correlograms allow exploratory spatial autocorrelation pattern detection using
Fig. 1 Overview of Austrian main rivers $\left(>4,000 \mathrm{~km}^{2}\right.$ catchment size) and 249 fish sampling sites with symbols for 4 European Fish Types (EFT): $(A)$ headwaters dominated by Salmo trutta fario, $(B)$ sections with low gradient dominated by Phoxinus phoxinus, $(C)$ types dominated by Thymallus thymallus, i.e., the greyling zone, $(F)$ lowland rivers

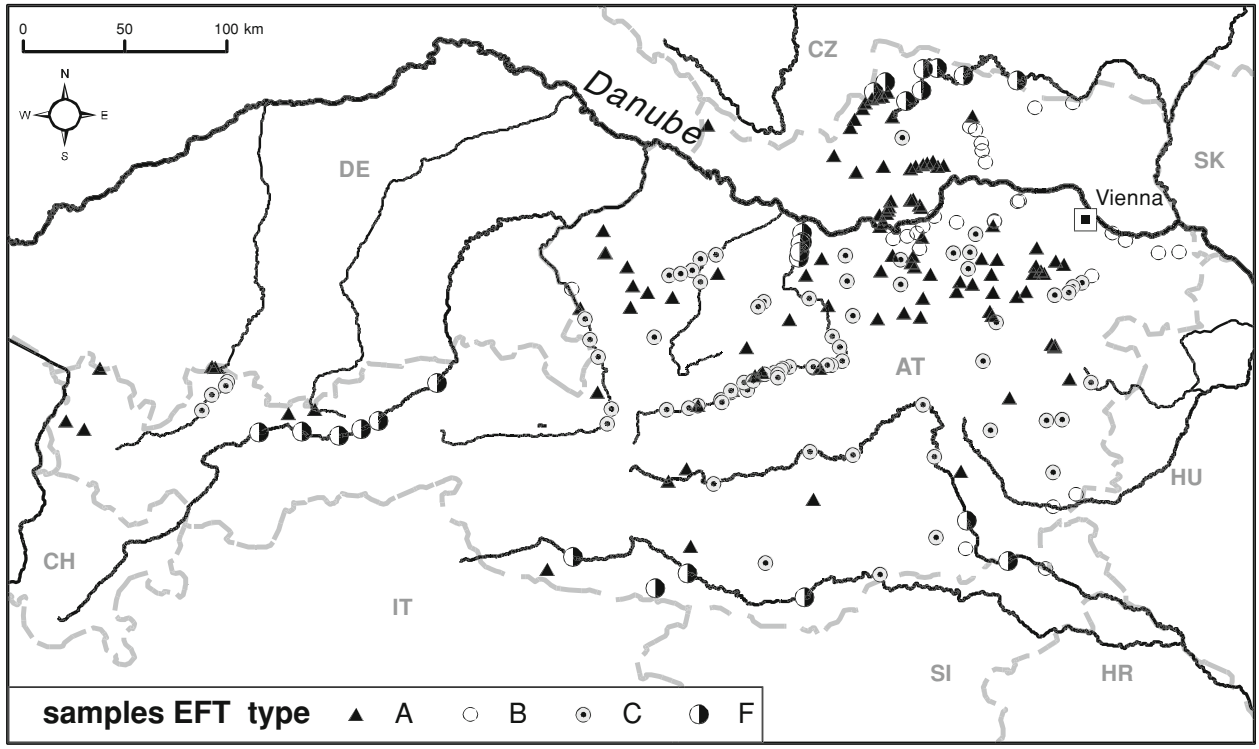


Moran's I coefficients, calculated for a set of distance classes. We set the tool to use default number of classes, default distance class size (equal number of pairs), symmetric distances (upper right distance matrix), and testing for significance by permutation 999 times. Threshold values for dispersed samplings that did not show autocorrelative patterns were drawn from the one distance class in Moran's I correlogram where Moran's I falls below 0.3 for both variables EFI and agri_du.

In the reduced dataset, replicative samples occurred in 25 subcatchments, five were sampled only once. Six subcatchments had more than 10 samples and therefore they were again tested for spatial autocorrelation. Spatial structure analysis (Moran's I correlogram) based on stream network distance between sampling sites within the subcatchments after reduction did not show significant autocorrelation patterns for the dependent variable EFI (highest in subcatchment Traun: Moran's I index $(\mathrm{MI})=0.23, p=0.32$ for distance class centre $29.3 \mathrm{~km}$ ). The main explanatory variable agri_du also showed no autocorrelation patterns in four out of six tested subcatchments. In subcatchment Mur and subcatchment March MI for each was still $0.57(p<0.05)$ in the distance class $34.6 \mathrm{~km}$ and $15 \mathrm{~km}$, respectively. Correlograms for urban_du showed no autocorrelation pattern. MI for past_du was significantly high in subcatchment Kamp only $(\mathrm{MI}=0.55 ; p=0.01)$ and forest showed no significant $\mathrm{MI}$ values in all but the subcatchment March $(\mathrm{MI}=0.48$; $p=0.04)$.

Further statistics were performed in R: A Language and Environment for Statistical Computing, version 2.11 (R Development Core Team 2009). We applied Pearson correlation two-tailed tests within land-use metrics, within fish metrics and also for relations between both. In order to reduce the number of dependent variables (biotic variables), we chose the fish metric that was best correlated to land use. Other fish metrics with a medium correlation $(|r|>0.5)$ to land use, while at the same time correlating $(|r| \geq 0.6)$ to the chosen fish metric, were omitted from further modelling.

Independent variables (land-use) with a minor occurrence (median $<1 \%$ ) were excluded from descriptive plots. Correlated land-use variables were kept in the modelling effort because they are not a problem in answer tree methods, whereas collinear variables are a major problem in regression analysis. Tree models deal better with nonlinearity and interaction between explanatory variables than does regression (Zuur et al. 2007). Principal component analysis (PCA) was applied for land-use variables. We used the command 'prcomp' from the package 'stats' in R. Wilcoxon rank sum test and Kruskal-Wallis test were used for testing differences between groupes in descriptive analysis of land use data. Alpha values in multiple pairwise tests were adjusted according to Bonferroni.

We used Classification and regression trees (CRT), a recursive partitioning method, to model the EFI and other fish metrics (as one dependent variable at a time) as a function of land-use variables (independent variables). CRT methods were available in the R-library (R-project CRAN) rpart. The 'rpart' algorithms follow the tree function of Breiman et al. (1984). In general, predicting the values of a continuous variable from one or more continuous and/or categorical predictor variables is a regressiontype problem. Common methods for regression-type problems are multiple regression or some general linear models (GLM). Nonetheless, classification-type problems are generally those in which categorical dependent variables are predicted from one or more continuous and/or categorical predictor variables. The dependent variables in this study were of continuous scale and, thus, the "anova" method was used to build the regression models that will be presented as binary trees.

Tree classification techniques, such as CRT, can produce predictions based on logical if-then conditions. Advantages of tree methods are their nonparametric basis, no implicit assumption of linearity, the simplicity of results for interpretation, and the ability of predictive classification for new observations.

One major issue when applying CRT is to avoid overfitting the model. In principal there are two mechanisms in choosing the 'right-sized' tree: first, stop generating new split nodes when an improvement of prediction becomes low or when certain criteria are met-termed forward pruning. Second, post pruning means pruning back highly branched trees to a simpler tree (Dakou et al. 2006). Reading and interpreting a 'big' tree with many nodes is more difficult. A good tree should be sufficiently complex to account for the known facts, but at the same time be as simple as possible. We used forward pruning criteria with maximum depth of tree $=3$ in an iterative process.

The model fitting algorithm 'rpart' (Therneau and Atkinson 1997) uses 10-fold cross-validation. The training set is split into 10 (roughly) equally sized parts and the tree is grown on nine parts while using the tenth for testing (Venables and Ripley 2003, p. 258). This procedure can be performed in 10 ways (always using another tenth for testing). The results are averaged and expressed as xerror, that is the cross-validated error estimation of the model as mean square error of the predictions at each split in the tree. We used xerror as an indicator for the model's performance and to compare different models by the 1-SE rule (Venables and Ripley 2003). One minus xerror stands for the explained variance by the regression tree model (hereafter, $R$-squared $=R^{2}$ ). 
The graphical output of a regression tree analysis is a branch-like graph splitting at the nodes by the split condition. Data for which the condition is true follow the left path. Vertical spacing between the nodes is proportional to improvement of the fit (Therneau and Atkinson 1997). In this study, we built models with the CRT method for each of the variables EFI, p_into, p_omni, and p_lith as dependent variables $(n=233)$. Two sub models for intolerant species on $\mathrm{EFT}=\mathrm{A}$ and $\mathrm{EFT}=(\mathrm{B}, \mathrm{C}, \mathrm{F})$ explored land use within these grouped river types.

\section{Study design}

We used 249 fish sampling sites from 106 distinct Austrian rivers nested in 30 subcatchments draining into the Danube (geographical overview see Fig. 1). The data set comprised rivers of 1 st to 7 th stream order. Most of the sites $(65 \%$, $n=162$ ) are 3 rd to 5 th order, 14 sites 1 st, 34 sites 2 nd, 33 sites 6 th, and 6 sites 7 th order. The Austrian sites were spread over a broad range of environmental characteristics and over four EFT. Altitude range of sampling sites: $139-1,193 \mathrm{~m}$ above sea level; river slope range: 0.001-13.2\%; upstream catchment size range: 1.65 to $\sim 10,200 \mathrm{~km}^{2}$.

Table 2 lists the species abundance in the dataset in total and for each EFT. Number of species in total and for the functional guilds of intolerant, lithophilic, and omnivorous are provided. Brown trout (S. trutta fario), greyling (T. thymallus), and chub (Leuciscus cephalus) were the most abundant species in the samples (34, 10.5, 9.4\%, respectively).

\section{Results}

We found seven medium-level correlations $(|r|>0.50)$ within 11 biotic variables (10 metrics, 1 Index). Pearson correlation coefficients of all pairs are shown in Table 3. Intolerant species, later seen as best correlated with agricultural land use, were correlated with omnivorous and

Table 2 Number of individuals and number of species in total and within river types

\begin{tabular}{|c|c|c|c|c|c|c|}
\hline & \multicolumn{4}{|c|}{ European fish type (EFT) } & \multirow[t]{2}{*}{ Total } & \multirow[t]{2}{*}{ Cum. $(\%)$} \\
\hline & A & $\mathrm{B}$ & $\mathrm{C}$ & $\mathrm{F}$ & & \\
\hline Number of intolerant species & 10 & 10 & 10 & 9 & 12 & \\
\hline Number of lithophilic species & 19 & 26 & 18 & 19 & 28 & \\
\hline Number of omnivorous species & 10 & 15 & 8 & 13 & 16 & \\
\hline Number of species total & 33 & 50 & 34 & 37 & 54 & \\
\hline Salmo trutta fario ${ }^{\mathrm{a}, \mathrm{b}}$ & $51.2 \%$ & $8.3 \%$ & $38.3 \%$ & $17.1 \%$ & $34.0 \%$ & 34.0 \\
\hline Thymallus thymallus ${ }^{\mathrm{a}, \mathrm{b}}$ & $2.3 \%$ & $1.3 \%$ & $22.9 \%$ & $19.9 \%$ & $10.5 \%$ & 44.5 \\
\hline Leuciscus cephalus ${ }^{\mathrm{b}, \mathrm{c}}$ & $5.7 \%$ & $19.4 \%$ & $5.9 \%$ & $11.4 \%$ & $9.4 \%$ & 53.9 \\
\hline Oncorhynchus mykiss ${ }^{\mathrm{b}}$ & $9.5 \%$ & $1.1 \%$ & $10.4 \%$ & $6.3 \%$ & $7.6 \%$ & 61.5 \\
\hline Cottus gobio $^{\mathrm{a}, \mathrm{b}}$ & $11.0 \%$ & $2.0 \%$ & $9.2 \%$ & $1.3 \%$ & $7.4 \%$ & 68.9 \\
\hline Gobio gobio & $4.4 \%$ & $12.7 \%$ & $0.5 \%$ & $5.6 \%$ & $5.1 \%$ & 74.0 \\
\hline Alburnus alburnus ${ }^{\mathrm{c}}$ & $0.0 \%$ & $18.5 \%$ & $0.0 \%$ & $4.0 \%$ & $4.5 \%$ & 78.6 \\
\hline Rutilus rutilus ${ }^{\mathrm{c}}$ & $4.5 \%$ & $5.6 \%$ & $0.6 \%$ & $10.4 \%$ & $4.1 \%$ & 82.7 \\
\hline Barbus barbus ${ }^{\mathrm{b}}$ & $0.1 \%$ & $3.7 \%$ & $7.1 \%$ & $1.2 \%$ & $3.2 \%$ & 85.9 \\
\hline Barbatula barbatula ${ }^{\mathrm{b}}$ & $5.1 \%$ & $2.1 \%$ & $0.7 \%$ & $2.1 \%$ & $2.7 \%$ & 88.6 \\
\hline Phoxinus phoxinus ${ }^{\mathrm{b}}$ & $3.3 \%$ & $2.7 \%$ & $1.1 \%$ & $1.2 \%$ & $2.3 \%$ & 90.9 \\
\hline Alburnoides bipunctatus ${ }^{\mathrm{a}, \mathrm{b}}$ & $0.4 \%$ & $6.8 \%$ & $0.5 \%$ & $3.4 \%$ & $2.2 \%$ & 93.1 \\
\hline Leuciscus leuciscus ${ }^{\mathrm{b}, \mathrm{c}}$ & $0.9 \%$ & $3.9 \%$ & $0.3 \%$ & $5.3 \%$ & $1.8 \%$ & 94.9 \\
\hline Chondrostoma nasus ${ }^{\mathrm{b}}$ & $0.0 \%$ & $2.6 \%$ & $0.7 \%$ & $2.4 \%$ & $1.1 \%$ & 96.0 \\
\hline Others & $1.4 \%$ & $9.2 \%$ & $1.8 \%$ & $8.6 \%$ & $4.0 \%$ & 100.0 \\
\hline$\%$ of total \# individuals & $100.0 \%$ & $100.0 \%$ & $100.0 \%$ & $100.0 \%$ & $100.0 \%$ & \\
\hline Number of individuals total & 19,861 & 12,370 & 17,927 & 5,997 & 56,155 & \\
\hline
\end{tabular}

Species names sorted by \% total; bold names are classified as general intolerant species (FAME-Consortium 2004)

EFT: A (headwater streams), B (lower gradient streams), C (greyling zone), F (lowland rivers)

${ }^{\text {a }}$ Intolerant species

${ }^{\mathrm{b}}$ Lithophilic species

c Omnivorous species 
Table 3 Pearson correlation coefficients for fish metrics

\begin{tabular}{|c|c|c|c|c|c|c|c|c|c|c|}
\hline & p_inse & p_omni & p_phyt & p_bent & p_rheo & p_long & p_pota & p_lith & p_into & p_tole \\
\hline p_inse & 1.00 & $0.2 * *$ & $0.24 * *$ & -0.10 & $0.25 * *$ & -0.01 & $0.18 * *$ & $0.36 * *$ & $0.22 * *$ & $0.3^{* * *}$ \\
\hline p_omni & $0.2 * *$ & 1.00 & $0.35 * *$ & $-0.49 * *$ & $-0.47 * *$ & -0.01 & $-0.35 * *$ & $0.49 * *$ & $0.69 * *$ & $0.39 * *$ \\
\hline p_phyt & $0.24 * *$ & $0.35^{* *}$ & 1.00 & $-0.4 * *$ & -0.04 & -0.13 & $-0.13 *$ & $0.47 * *$ & $0.37 * *$ & $0.44 * *$ \\
\hline p_bent & -0.10 & $-0.49 * *$ & $-0.4 * *$ & 1.00 & $0.64 * *$ & 0.11 & $0.32 * *$ & $-0.41 * *$ & $-0.43^{* *}$ & $-0.35 * *$ \\
\hline p_rheo & $0.25^{* *}$ & $-0.47 * *$ & -0.04 & $0.64 * *$ & 1.00 & 0.06 & $0.7 * *$ & $-0.15^{*}$ & $-0.4^{* *}$ & 0.03 \\
\hline p_long & -0.01 & -0.01 & -0.13 & 0.11 & 0.06 & 1.00 & $0.13 *$ & -0.14 & -0.08 & $-0.27 * *$ \\
\hline p_pota & $0.18 * *$ & $-0.35^{* * *}$ & $-0.13 *$ & $0.32 * *$ & $0.7 * *$ & $0.13^{*}$ & 1.00 & 0.04 & $-0.41 * *$ & -0.03 \\
\hline p_lith & $0.36 * *$ & $0.49 * *$ & $0.47 * *$ & $-0.41^{* *}$ & $-0.15^{*}$ & -0.14 & 0.04 & 1.00 & $0.58 * *$ & $0.53 * *$ \\
\hline p_into & $0.22 * *$ & $0.69 * *$ & $0.37 * *$ & $-0.43^{* *}$ & $-0.4 * *$ & -0.08 & $-0.41 * *$ & $0.58 * *$ & 1.00 & $0.44 * *$ \\
\hline p_tole & $0.3^{* *}$ & $0.39 * *$ & $0.44 * *$ & $-0.35^{* *}$ & 0.03 & $-0.27 * *$ & -0.03 & $0.53^{* *}$ & $0.44 * *$ & 1.00 \\
\hline EFI & $0.63 * *$ & $0.42 * *$ & $0.48 * *$ & 0.04 & $0.4^{* * *}$ & $0.16^{*}$ & $0.38 * *$ & $0.65 * *$ & $0.47 * *$ & $0.58 * *$ \\
\hline
\end{tabular}

Values $|r|>0.30$ in bold

** Correlation is significant at the 0.01 level (2-tailed)

* Correlation is significant at the 0.05 level (2-tailed)

lithophilic species ( $r$ values $0.69,0.58$, respectively; both $p<0.01$ ).

In general, agriculture and forest were the predominant land-use categories; these were negatively correlated $(-0.43, p<0.01, n=249$; Table 4$)$. The median value of agriculture was $4.2 \%$, the 3 rd quartile at $31.2 \%$. The median value of forest was $50.1 \%$. The other categories exhibited lower median values: shrubs $=1.3 \%$, pasture $=8.3 \%$, urban $=1.7 \%$.

In a PCA with urban, agriculture, pasture, forest, and shrubland, the first component explained $33.9 \%$ of the variation, the second component $27.8 \%$ and the third component $24.3 \%$. Hence, the first three principal components (PC) explained $85.9 \%$ of the variation. The biplot (Fig. 2) of the first two PCs of all five land-use variables showed that forest and pasture are similarly loaded and that urban and shrubland are clearly inversely related. Agriculture was the main antagonist to forest. In the first PC of the rotated loadings matrix, agriculture loads with 0.67 , shrubland with -0.56 urban with 0.42 . In the second PC, forest loads with 0.59 , pasture with 0.54 , shrubland with -0.43 .

From correlation analysis, we learned that coefficients for urbanisation were low $(|r| \leq 0.25, p<0.05)$ with all other categories. Pasture correlated with all coefficients below absolute values of 0.27 (Table 4).

We observed differences in land-use composition between four EFTs. The proportions of forest were quite high (median values $>50 \%$ ) for fish sampling sites of type A (headwaters) and type $\mathrm{C}$ (greyling zone), whereas agriculture was very low (Fig. 3a, b). Agricultural land use was highest (median $=38.2 \%$ ) in type $\mathrm{B}$ (lower-gradient rivers) (Fig. 3b). Pasture and urban land reached lower levels and did not differ much between the fish types (Fig. 3c, d).
Table 4 Pearson correlation coefficients for land-use variables and fish metrics

\begin{tabular}{|c|c|c|c|c|c|}
\hline & urban_du & agri_du & past_du & fores_du & scrub_du \\
\hline urban_du & 1.00 & $0.16^{*}$ & $0.25 * *$ & $-0.15^{*}$ & $-0.25 * *$ \\
\hline agri_du & $0.16^{*}$ & 1.00 & $-0.27 * *$ & $-0.43^{* *}$ & $-0.53 * *$ \\
\hline past_du & $0.25^{* *}$ & $-0.27 * *$ & 1.00 & -0.03 & $-0.15^{*}$ \\
\hline fores_du & $-0.15^{*}$ & $-0.43 * *$ & -0.03 & 1.00 & $-0.33 * *$ \\
\hline scrub_du & $-0.25^{* *}$ & $-0.53 * *$ & $-0.15^{*}$ & $-0.33^{* *}$ & 1.00 \\
\hline p_inse & -0.07 & $-0.25^{* *}$ & -0.01 & $0.28 * *$ & -0.01 \\
\hline p_omni & $-0.19 * *$ & $-0.48 * *$ & -0.04 & $0.18 * *$ & $0.38 * *$ \\
\hline p_phyt & -0.07 & $-0.23 * *$ & 0.02 & 0.14 & $0.15^{*}$ \\
\hline p_bent & $0.13^{*}$ & $0.36 * *$ & 0.08 & -0.09 & $-0.33 * *$ \\
\hline p_rheo & 0.11 & $0.13^{*}$ & 0.15 & 0.09 & $-0.26^{* *}$ \\
\hline p_long & -0.05 & $-0.19 * *$ & $0.18 * *$ & 0.06 & -0.01 \\
\hline p_pota & $0.17 * *$ & 0.03 & $0.19 * *$ & 0.09 & $-0.2 * *$ \\
\hline p_lith & $-0.13^{*}$ & $-0.52 * *$ & $0.16^{*}$ & 0.14 & $0.36 * *$ \\
\hline p_into & $-0.32 * *$ & $-0.56 * *$ & -0.03 & $0.21 * *$ & $0.45 * *$ \\
\hline p_tole & -0.09 & $-0.27 * *$ & -0.02 & $0.21 * *$ & 0.10 \\
\hline EFI & -0.09 & $-0.45 * *$ & $0.16^{*}$ & $0.3^{* * *}$ & $0.18 * *$ \\
\hline
\end{tabular}

Values $|r|>0.30$ in bold

** Correlation is significant at the 0.01 level (2-tailed)

* Correlation is significant at the 0.05 level (2-tailed)

The plots also showed a high variation in forest and agriculture (SD 0.13-0.20, 0.12-0.28, respectively) and that variation was less for pasture and urban $(\mathrm{SD}<0.11$, $\mathrm{SD}<0.04$, respectively). Tests for differences (Wilcoxon Rank Sum Test) between the EFT groups showed significances (see Fig. 3) for all but one EFT pairing within forest and agriculture ratios each. Pasture had only two and urbanisation had three pairs with significant differences. 


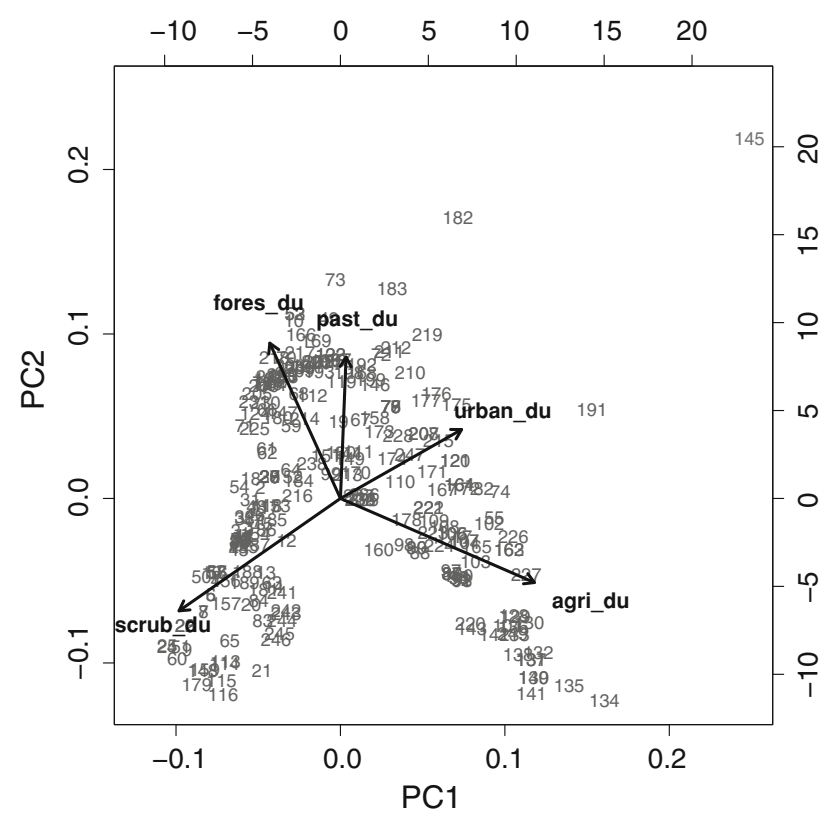

Fig. 2 Biplot of first two principal components (PC) of five land-use variables; variance explained by first component $33.9 \%$, second component $27.8 \%$

Correlation analyses supported a statistical relationship between agricultural land use and the ecological status of rivers (Table 4). The results showed that values of the European Fish Index were negatively correlated with the amount of agriculture in the catchment $(r=-0.45$, $p<0.01, n=249)$. Correlation between urbanised land and the fish index was very low and not significant $(r=$ $-0.09, p \geq 0.05$ ).

Agriculture in the catchment was highly correlated with omnivorous $(r=-0.48, p<0.01)$, lithophilic $(r=-0.52$, $p<0.01)$, and intolerant $(r=-0.56, p<0.01)$ species metrics. The best relating metrics in respect of forest were insectivorous and intolerant species $(r=0.28$ and $r=0.21$, respectively, both $p<0.01$ ). Finally, urbanisation-with generally weaker coefficients-was best correlated with intolerant species $(r=-0.32, p<0.01)$. Hence, we used intolerant species for further modelling because of their best correlation with agricultural and urban land use. Omnivorous and lithophilic species were considered redundant because they showed a high correlation $(r>0.58)$ with intolerant species.

We explored and tested the relationship between land use and ecological status by box-whisker plots of the amounts of agriculture, forest, and urbanisation in the catchment against all five EFI classes (Fig. 4). The observed patterns showed a good separation of sites with high or good status from sites in poor or bad condition. The moderate class had a large overlap with the other status classes and indicates a transition class. Pairwise nonparametric test statistics (Wilcoxon Rank Sum Test) with (a) forest

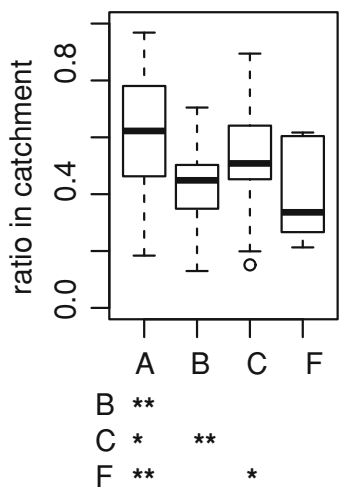

(c) pasture

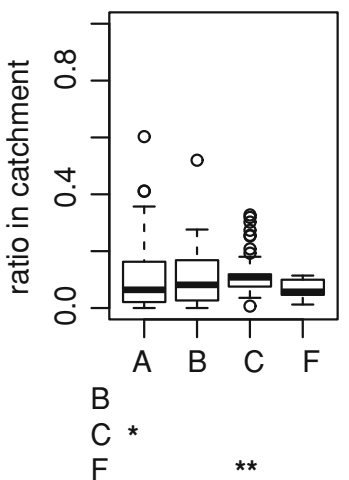

(b) agriculture

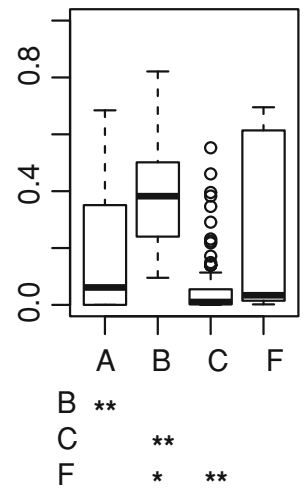

(d) urban

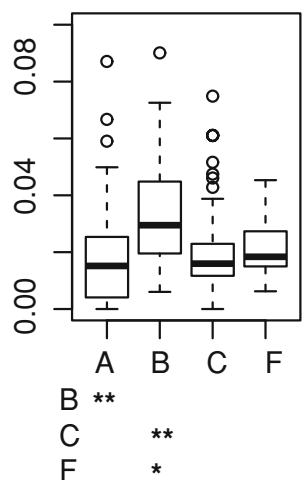

Fig. 3 Four boxplots showing ratios of land-use categories within four European Fish Types (EFT): $(A)$ headwaters dominated by Salmo trutta fario, $n=102$, $(B)$ sections with low gradient dominated by Phoxinus phoxinus, $n=30$, $(C)$ types dominated by Thymallus thymallus, i.e., greyling zone, $n=75,(F)$ lowland rivers; **pairwise Wilcoxon Rank Sum Test was significant at the 0.01 level; *pairwise Wilcoxon Rank Sum Test was significant at the 0.05 level; alpha adjustment method: Bonferroni

Bonferroni-adjusted alpha attest significant differences between several groups (Fig. 4). Agriculture in the catchment differed significantly $(p<0.05)$ between status classes 'high' and 'moderate', 'good' and 'moderate', and 'good' and 'bad'. Forest differed between 'high' and 'moderate' and 'high' and 'bad'. Differentiation is not significant for any pairing of urbanisation. When visually defining separation values, however, we expect thresholds at a level of $\sim 40 \%$ for agriculture, $\sim 45 \%$ for forest, and $\sim 2.5 \%$ for urbanised land.

Modelling biotic response variables with regression trees

When loading all land-use variables and EFT into one model (Fig. 5) with EFI as the dependent variable, the model used agriculture, forest, urbanisation, and EFT for tree construction. Agriculture occurred as a first-split 
(a) EFI and agriculture

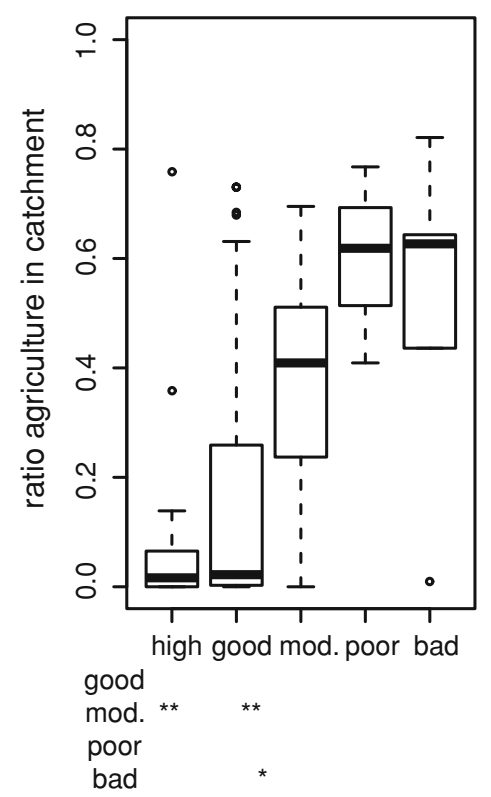

(b) EFI and forest

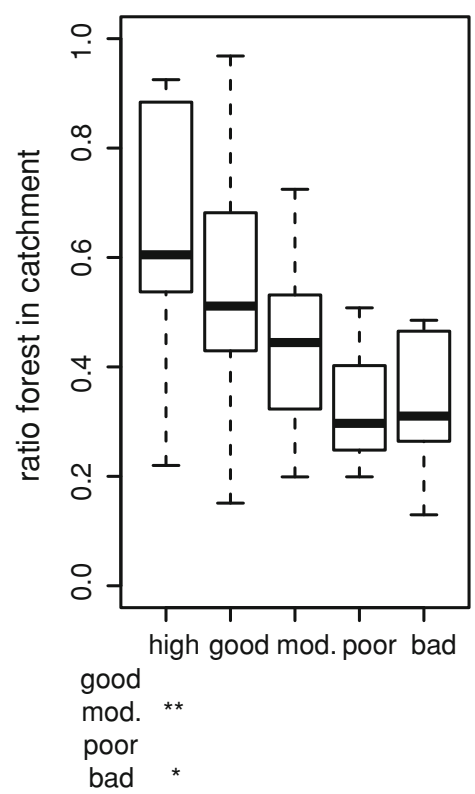

(c) EFI and urban

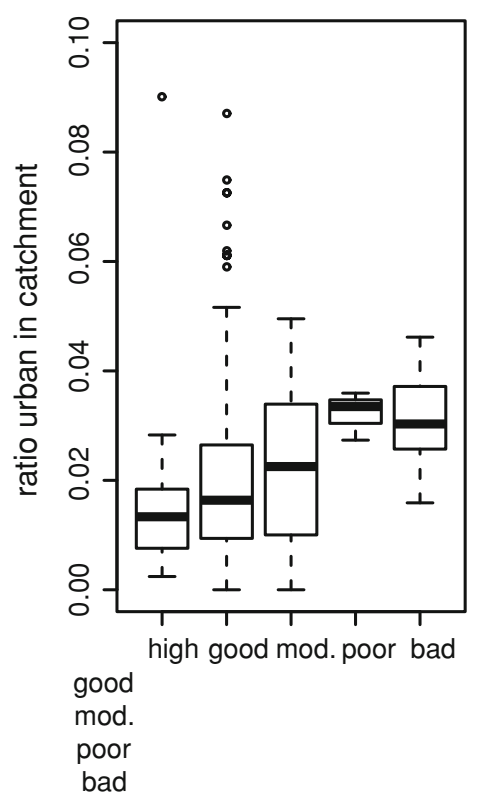

Fig. 4 Box plots of five ecological status classes; number of sites in plots $($ high $=20$, good $=194$, moderate $=27$, poor $=3$, bad $=5$ ); $\mathbf{a}$ amounts of agriculture; $\mathbf{b}$ amounts of forest and $\mathbf{c}$ urbanised land by ecological status; $Y$-axis of urban is scaled to a range from 0 to 0.10

variable at $23.3 \%$, and urban land differentiated at the third level at $>2.9 \%$ at both paths. Sites of EFT $=$ F combined with more than $23.3 \%$ agriculture had the least mean value of EFI (0.33/moderate status). Other paths revealed a cumulative effect by combinations of agriculture and urbanisation. Sites having both more than $23.3 \%$ agriculture and more than $2.9 \%$ urbanisation were in moderate status (mean EFI $=0.45$ ), whereas those combined with $<2.9 \%$ urban are in high status (mean $\mathrm{EFI}=0.52$ ). The path combining agriculture $<23.3 \%$ and urbanisation $>4.4 \%$ had a low impact on fish and the terminal node value was 0.53 (good status); agriculture $<23.3 \%$ combined with urban $<4.4 \%$ had high status (mean $\mathrm{EFI}=0.6$ ). Forest also occurred as split criteria at a percentage of $44.3 \%$ but made little contribution to distinguishing between EFI in this model. The overall $R^{2}$ after five splits in this EFI model with three variables of land use and one for EFT was 0.35, but dropped to 0.15 after cross-validation.

In the next step, we built a model with four land-use categories (urban, agriculture, pasture, forest) and EFT as independent and the relative number of intolerant species as a dependent variable (Fig. 6). Poor status (mean $\mathrm{EFI}=0.25$ ) occurred in the path with agriculture $\geq 7.3 \%$, forest $<56.4 \%$ and pasture $<18.4 \%$. Compared to the previous model with the EFI (Fig. 5), this model of intolerant species also revealed a cumulative effect of agriculture and urbanisation in the catchment. Sites with both more than 7.3\% agriculture and more than $2.0 \%$ urban held sites of because of low ratio levels in this category; **pairwise Wilcoxon Rank Sum Test was significant at the 0.01 level; *pairwise Wilcoxon Rank Sum Test was significant at the 0.05 level; alpha adjustment method: Bonferroni

moderate status (mean $=0.42$ ). Urban $\geq 1.8 \%$ but agriculture $<7.3 \%$ was still in good (nearly high) status (mean value $0.64)$. The rightmost path with agriculture $(<7.3 \%)$ in a noncumulative association with urban $(<1.8 \%)$ yielded high mean metric value of 0.81 (high status). High percentages of forest ( $\geq 56.4, \geq 64.6 \%$ ) led to values of higher integrity.

The result revealed a different reaction in EFT (Fig. 6). If the amount of agriculture was below $7.3 \%$ (right path), then the data split into EFT A dominated by brown trout in contrast to the other types. Metric values of intolerant species dropped to moderate/good status in EFT A compared to high/good in all other types. Finally this model of a particular fish metric has better explanatory power $\left(R^{2}=0.46\right)$ than for the EFI itself and seems to be more stable. $R^{2}$ before cross-validation was 0.53 .

Models on sub datasets of EFT A (headwaters) and lumped EFTs (B, C, F-river slope lower than in A), both with intolerant species as dependent variable, had very different explanatory power (data not shown):

In the $\mathrm{EFT}=\mathrm{B}, \mathrm{C}, \mathrm{F}$ model, agriculture and urbanisation acted in the same manner and at the same levels as in the general model on intolerants (Fig. 6), where we observed a cumulative effect of agriculture and urbanisation. The $R^{2}$ value of the $\mathrm{EFT}=\mathrm{B}, \mathrm{C}, \mathrm{F}$ model was 0.58 (summary see Table 5).

In the EFT A model, forest was first split variable at $67.6 \%$, urban was second at $2.6 \%$ and $R^{2}$ of the tree model was 0.10 (cross-validated) (summary see Table 5). 
Fig. 5 Regression tree for EFI based on land-use categories in the catchment draining to the fish sampling sites; $n=233$; $R^{2}=0.15$; true split criteria at nodes follows left path
Fig. 6 Regression tree for metric of relative number of intolerant species in the EFI; independent variables are agriculture, forest, pasture, urban and European Fish Types (EFT); $n=233 ; R^{2}=0.46$; true split criteria at nodes follows left path
$\mathrm{EFI}$
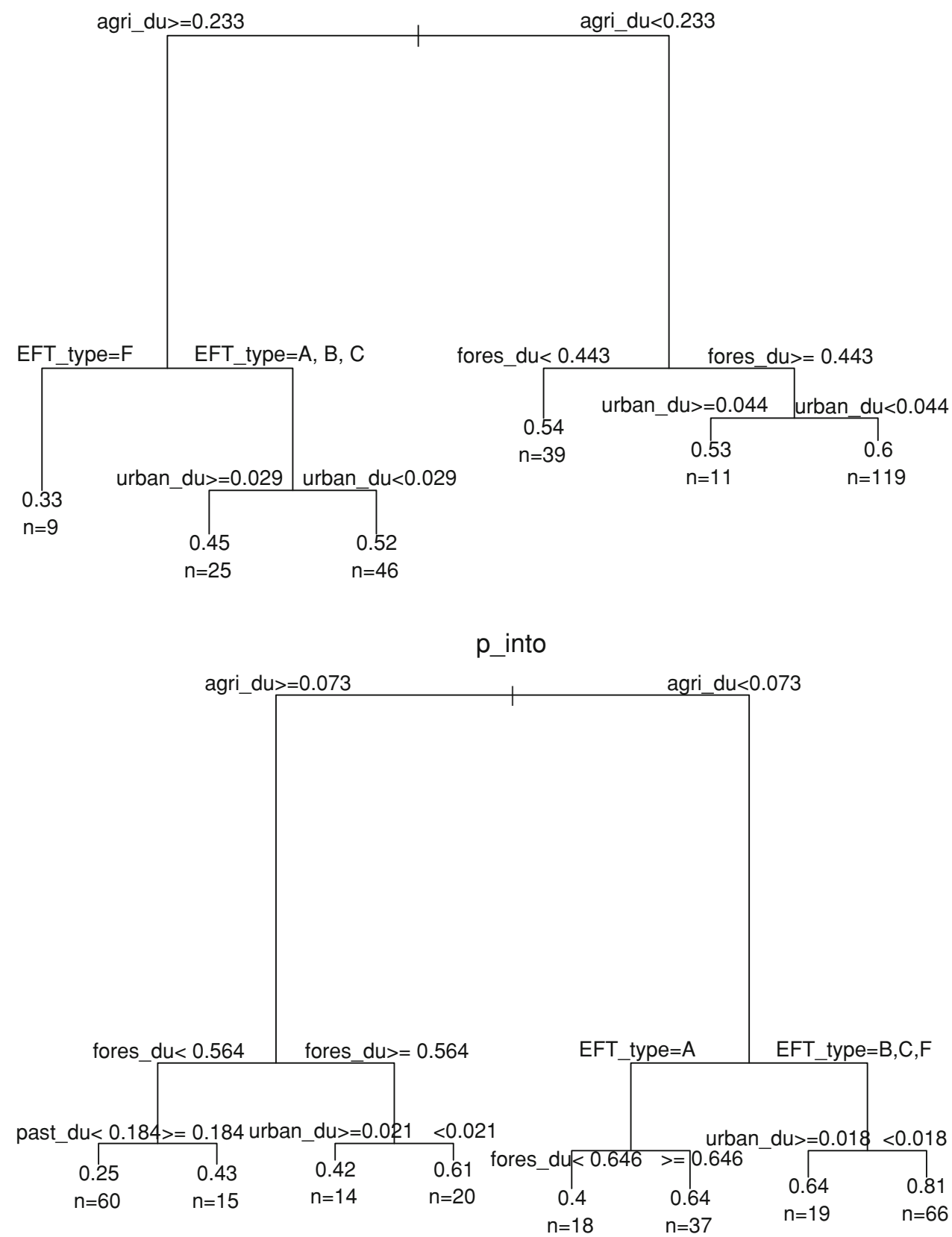

Agriculture was an input variable, but not used by the $\mathrm{EFT}=\mathrm{A}$ model. The terminal node with worst ecological status (mean EFI $=0.13 /$ bad status) contained sites with urbanisation exceeding $2.6 \%$ and pasture below $11.3 \%$. Pasture occurred in a positive trend to ecological integrity within this model of headwaters $(\mathrm{EFT}=\mathrm{A})$.

\section{Discussion}

Agriculture was the primary explanatory variable in all but one tree model (Table 5). Agriculture as split criteria occurred at three levels: at $23.3 \%$ but also at $\sim 7.3$ and $36-40 \%$. Very often, urban land served as the secondary split variable at about $2 \%$, with minimum $1.8 \%$ and maximum even at $4.4 \%$. So, the regression tree method affirmed our interpretation of thresholds in the descriptive analysis. There was a clear interaction of agriculture and urban. Sites with more than $7.3 \%$ agriculture and more than $2.0 \%$ urban land were likely to result in poor or moderate status. Urbanisation acted more strongly in river types dominated by brown trout ( $S$. trutta fario) $(\mathrm{EFT}=\mathrm{A})$ than in river types of lower gradients $(\mathrm{EFT}=\mathrm{B}, \mathrm{C}, \mathrm{F})$. The model for the relative number of 
Table 5 Summary of the model results for fish metrics as dependent variable and land-use categories as independent variables

\begin{tabular}{|c|c|c|c|c|c|c|}
\hline Model title & $\mathrm{y}$ & Independent used & 1st level split & 2nd level split & $R^{2}$ & $N$ \\
\hline $\mathrm{EFI}-\mathrm{AT}$ & EFI & Agri, fores, urban & Agri $23.3 \%$ & Urban $\sim 3 \%$ & 0.15 & 249 \\
\hline AT intolerants & P_into & Agri, fores, urban, EFT & Agri $7.3 \%$ & Fores $44 \%$, urban $\sim 2 \%$ & 0.46 & 249 \\
\hline AT omnivorous & p_omni & Agri, urban & Agri $7.3 \%$ & Urban $\sim 2 \%$ & 0.17 & 249 \\
\hline AT lithophilic & p_lith & Agri, urban, EFT & Agri $40 \%$ & Urban $3.3 \%$ & 0.39 & 249 \\
\hline $\mathrm{EFT}=\mathrm{A}$, intolerants & p_into & Fores, past, urban & Fores $67.6 \%$ & Urban $\sim 2.5 \%$ & 0.09 & 102 \\
\hline $\mathrm{EFT}=\mathrm{B}, \mathrm{C}, \mathrm{F}$ intolerants & p_into & Agri, urban & Agri $8 \%$ & Agri $36.7 \%$, urban $1.8 \%$ & 0.58 & 131 \\
\hline
\end{tabular}

Abbreviations see Table 1

intolerant species had better explanatory power than for EFI.

Our study showed that multiple land-use categories had an effect on fish. Agricultural land use had the strongest detrimental effect. Percentages of agriculture in the catchment were negatively correlated with the European Fish Index (EFI). Many studies have found comparable results for selected small to medium-sized catchments of 2nd to 3rd order rivers (Allan 2004b; Richards et al. 1996; Roth et al. 1996); our findings corroborated this relationship for the Austrian dataset from small to larger rivers (up to 7th order) and across four different river types. Urban areas in the catchment showed strong effects on fish metrics even at very small percentages. Snyder et al. (2003) and Wang et al. (2003) also discussed a disproportionately large effect of urban land use. Yet, significance of the test results for urban, agriculture, and forest within EFI status classes are limited due to an uneven distribution of samples in high to bad status. Snyder et al. (2003) found no correlation between agriculture (lumped with pasture) and biota and recommended examining more specific land-use categories such as grazing versus row-crop agriculture. Our findings identified pasture (grazing and grassland) as less influential than agriculture (arable land and permanent crops).

Moerke and Lamberti (2006) also related four categories to fish assemblage structure and found higher IBI scores in forested streams compared to urban and agricultural streams. Our results go beyond mere correlation (Steel et al. 2010) because we applied new methods and identified thresholds at which biota react. Intolerant, lithophilic, and omnivorous species reacted most strongly to agriculture and urban development. Metrics for insectivorous and migratory species were less correlated to land use. Moerke and Lamberti (2006) used metrics of general tolerance and showed a positive association between sensitive species and higher percentages of forest in the catchment, and between tolerant fish and changes in land use (agriculture, urban). Pess et al. (2002) reported positive correlated densities of salmon with forest cover in the watershed. Our findings revealed that a fish metric of intolerance to general disturbance (p_into) is a better indicator than the EFI. We hypothesise that these species react to both direct (e.g., toxins, nutrients) and indirect (e.g., sedimentation, hydrologic alteration) effects of land use. Wang et al. (2003) also used percentage of intolerants and found that thresholds for urban land cover (measured as impervious surface area) had detrimental effects on fish at $11 \%$. Among four aquatic organism groups (diatoms, macrophytes, benthic macroinvertebrates and fish) fish were found to respond less strongly to catchment land use than to eutrophication/ organic pollution gradients (Hering et al. 2006). Hering et al. (2006) found the strongest response for lithophilic and limnophilic species and related this to direct or indirect effects of land-use on habitat quality. Hering et al. also discussed effects of land-use acting through numerous cause-effect relationships that are difficult to identify.

Few studies have dealt with relative effects of multiple land-use categories on stream ecosystems (Moerke and Lamberti 2006; Van Sickle et al. 2004; Snyder et al. 2003). Moerke and Lamberti (2006) evaluated forest, urban, agriculture and wetlands. Snyder et al. (2003) additionally used water and barren land, but in both studies only forest, agriculture and urban were frequent and associated strongly enough for further analysis. Using regression analysis, Snyder et al. (2003) explained 63\% of IBI variation by urban land in the catchment alone. Neither forest nor agriculture explained a significant amount of the remaining variation in IBI after accounting for the effects of urban land use. In our study, using answer tree models, we determined a cumulative effect of agriculture and urban land use. Urban or agriculture alone resulted in a lower detrimental effect than when combined.

\section{River-type-specific reactions}

The brown trout assemblage type (EFT A) showed a stronger decrease in ecological status than river types of lower sections (greyling zone, lowland rivers). In the latter fish types $(\mathrm{EFT}=\mathrm{BCF})$, the cumulative effect of agriculture and urban was better pronounced than in headwaters. In general, agriculture correlated best to fish metrics and 
EFI, whereas all other land-use categories remained at a very low correlation level. Headwaters, however, seemed to be very sensitive although at low levels of agriculture $(<7.3 \%)$ and highly forested catchments $(<64.6 \%)$. We hypothesise that the underlying mechanisms are effects of hydrology (e.g., increased peak runoff from impervious surfaces), morphological alteration (e.g., channelization) and removal of riparian vegetation (e.g., reduced shading, increased water temperature) (Allan 2004b), and that they act more strongly on small headwater streams. Additionally, by nature, trout rivers are low-species-number rivers with intolerant species and, therefore, intolerant-speciesmetric responded more sensitively to disturbance.

Hering et al. (2006) produced weak correlation results for mountain streams, while in lowland stream types the explanatory power of the fish metrics was at a higher level $\left(r^{2}=0.4\right)$. These findings are somehow contradictory to our findings because headwaters respond even more sensitively than other EFTs. However, a model for the headwater fishtype $(\mathrm{EFT}=\mathrm{A})$ was much less powerful than for streams of lower gradients $(\mathrm{EFT}=\mathrm{B}, \mathrm{C}, \mathrm{F})$. The explanatory power of our models of land-use seem to be comparable to Hering et al. (2006) with maximum at $R^{2}=0.46$. Nevertheless, we are aware of bias in the model for headwaters. Full land-use gradients are limited in our dataset because most headwaters are located in less developed landscapes.

\section{Conclusions}

With this study we provide catchment-level relationships for land use covering headwater streams (brown trout) to medium- (greyling) and large-sized rivers in Austria. Moerke and Lamberti (2006) have already concluded that additional replicated, catchment-level studies in other geographic areas will enhance our knowledge of how land use affects stream ecosystems. Such findings help identify characteristics that make streams more or less sensitive to land-use change.

The regression tree models we used are very simple and based on a large sample of sites. They can explain a moderate amount of variability in biotic integrity based on a few land-use categories (urban areas, agriculture, pasture, and forest). These results are promising as building blocks for designing models of cascades that represent mechanistic relationships.

The present study does not explain the full pathways from land use via physical habitat, water quality and/or hydrologic alteration to a resulting biological impact, but the results do go beyond mere correlative analysis. Research into underlying mechanisms remains a challenge (Steel et al. 2010; Wang et al. 2006a). Based on the current findings, it will be possible to develop first steps of characteristic cause and effect pathways for selected river types.

Acknowledgments Work on this manuscript was funded by the Austrian Science Fund (FWF, research project LANPREF, contract number P 21735-B16). Basic ideas for this work arose within the $\mathrm{EFI}+$ project supported by the European Commission under FP6 (contract number 044096), and our sincere thanks go to all members of the EFI + consortium. We thank Andreas Melcher for valuable discussions on early stages of the manuscript. Ashley Steel gave precious input to consistency of the manuscript, discussion of the results and the English, thank you. Two anonymous reviewers addressed several substantive issues to improve the manuscript.

Open Access This article is distributed under the terms of the Creative Commons Attribution Noncommercial License which permits any noncommercial use, distribution, and reproduction in any medium, provided the original author(s) and source are credited.

\section{References}

Allan JD (2004a) Influence of land use and landscape setting on the ecological status of rivers. Limnetica 23:187-198

Allan JD (2004b) Landscapes and riverscapes: the influence of land use on stream ecosystems. Annu Rev Ecol Evol S 35:257-284

Allan JD, Johnson LB (1997) Catchment-scale analysis of aquatic ecosystems. Freshw Biol 37:107-111

Allan JD, Erickson DL, Fay J (1997) The influence of catchment land use on stream integrity across multiple spatial scales. Freshw Biol 37:149-161

Beechie TJ, Sear DA, Olden JD, Pess GR, Buffington JM, Moir H, Roni P, Pollock MM (2010) Process-based principles for restoring river ecosystems. Bioscience 60:209-222

Beyer HL (2004) Hawth's Analysis Tools for ArcGIS. Available at http://www.spatialecology.com/htools. Accessed $11 \mathrm{Feb} 2008$

Botequilha Leitao A, Miller J, Ahern J, McGarigal K (2006) Measuring landscapes. Island, Washington, DC

Breiman L, Friedman J, Stone CJ, Olshen RA (1984) Classification and regression trees. Chapman and Hall/CRC, Boca Raton

CEN (2003) Water quality-sampling of fish with electricity, EN 14011. European Committee for Standardisation, Brussels

Dakou E, D'heygere T, Dedecker AP, Goethals PLM, LazaridouDimitriadou M, Pauw N (2006) Decision tree models for prediction of macroinvertebrate taxa in the river axios (northern Greece). Aquat Ecol 41:399-411

Durance I, Lepichon C, Ormerod SJ (2006) Recognizing the importance of scale in the ecology and management of riverine fish. River Res Appl 22:1143-1152

EC of European Parliament (2000) Water framework directiveEstablishing a framework for community action in the field of water policy. Off J Eur Comm L327:1-72

ESRI (2008) ArcGIS Desktop, Version 9.3, ArcInfo license. Redlands, CA

FAME-Consortium (2004) Manual for Application of the European Fish Index-EFI. A fish-based method to assess the ecological status of European rivers in support of the Water Framework Directive (Version 1.1, January 2005). Available at: http://fame.boku. ac.at/downloads/manual_Version_Februar2005.pdf. Accessed 2 Apr 2008

Gergel SE, Turner MG, Miller JR, Melack JM, Stanley EH (2002) Landscape indicators of human impacts to riverine systems. Aquat Sci 64:118-128 
Hering D, Johnson RK, Kramm S et al (2006) Assessment of European streams with diatoms, macrophytes, macroinvertebrates and fish: a comparative metric-based analysis of organism response to stress. Freshw Biol 51(9):1757-1785

Huet M (1949) Aperçu des relations entre la pente et les populations piscicoles des eaux courantes. Schweiz Z Hydrol 11:332-351

Illies J, Andrássy I (1978) Limnofauna europaea-a checklist of the animals inhabiting European inland waters, with accounts of their distribution and ecology (except protozoa), vol 2, Second revised edn. Gustav Fischer Verlag, Stuttgart, NY

Karr JR (1981) Assessment of biotic integrity using fish communities. Fisheries 6:21-27

Melcher A, Schmutz S, Haidvogl G, Moder K (2007) Spatially based methods to assess the ecological status of European fish assemblage types. Fish Manag Ecol 14:453-463

Miltner R, White D, Yoder C (2004) The biotic integrity of streams in urban and suburbanizing landscapes. Landsc Urban Plan 69:87-100

Moerke AH, Lamberti GA (2006) Relationships between land use and stream ecosystems: a multistream assessment in southwestern Michigan. Am Fish Soc Symp 2006:323-338

Noble RAA, Cowx IG, Goffaux D, Kestemont P (2007) Assessing the health of European rivers using functional ecological guilds of fish communities: standardising species classification and approaches to metric selection. Fish Manag Ecol 14(6):381-392

Omernik JM, Bailey RG (1997) Distinguishing between watersheds and ecoregions. J Am Water Resour Assoc 33:935-949

Pess GR, Montgomery DR, Steel EA, Bilby RE, Feist BE, Greenberg HM (2002) Landscape characteristics, land use, and coho salmon (Oncorhynchus kisutch) abundance, Snohomish River, Washington, USA. Can J Fish Aquat Sci 59:613-623

Poff NL (1997) Landscape filters and species traits: Towards mechanistic understanding and prediction in stream ecology. J N Am Benthol Soc 16:391-409

Pont D, Hugueny B, Beier U, Goffaux D, Melcher A, Noble R, Rogers C, Roset N, Schmutz S (2006) Assessing river biotic condition at a continental scale: a European approach using functional metrics and fish assemblages. J Appl Ecol 43:70-80

Pont D, Hugueny B, ROGERS C (2007) Development of a fish-based index for the assessment of river health in Europe: The European fish index. Fish Manag Ecol 14:427-439

R Development Core Team (2009) R: A language and environment for statistical computing. Vienna, Austria

Rangel TF, Diniz-Filho JAF, Bini LM (2010) SAM: a comprehensive application for spatial analysis in macroecology. Ecography $33: 1-5$
Richards C, Johnson LB, Host GE (1996) Landscape-scale influences on stream habitats and biota. Can J Fish Aquat Sci 53:295-311

Roth NE, Allan JD, Erickson DL (1996) Landscape influences on stream biotic integrity assessed at multiple spatial scales. Landscape Ecol 11:141-156

Snyder CD, Young JA, Villella R, Lemarie DP (2003) Influences of upland and riparian land use patterns on stream biotic integrity. Landscape Ecol 18:647-664

Steel EA, Hughes RM, Fullerton AH, Schmutz S, Young J, Fukushima M, Muhar S, Poppe M, Feist BE, Trautwein C (2010) Are we meeting the challenges of landscape-scale riverine research? A review. Living Rev Lands Res 4:1

Stewart JS, Wang L, Lyons J, Horwatich JA, Bannerman R (2001) Influences of watershed, riparian-corridor, and reach-scale characteristics on aquatic biota in agricultural watersheds. J Am Water Resour Assoc 37:1475-1487

Therneau TM, Atkinson EJ (1997) An introduction to recursive partitioning using the rpart routines. http://www.mayo.edu/hsr/ techrpt/61.pdf (cited on 12/03/2010)

Van Sickle J, Baker J, Herlihy A, Bayley P, Gregory S, Haggerty P, Ashkenas L, Li J (2004) Projecting the biological condition of streams under alternative scenarios of human land use. Ecol Appl 14:368-380

Venables WN, Ripley BD (2003) Modern applied statistics with S, 4th edn. Springer, New York

Vogt JV, Soille P, Jager AD, Rimaviciute E, Mehl W, Foisneau S, Bodis K, Dusart J, Paracchini ML, Haastrup P, Bamps C (2007) A pan-European river and catchment database. European Commission, Joint Research Center, Institute for Environment and Sustainability, Luxembourg

Wang L, Lyons J, Kanehl P, Bannerman R (2001) Impacts of urbanization on stream habitat and fish across multiple spatial scales. Environ Manage 28:255-266

Wang L, Lyons J, Kanehl P (2003) Impacts of urban land cover on trout streams in Wisconsin and Minnesota. Trans Am Fish Soc 132:825-839

Wang L, Seelbach PW, Hughes RM (2006a) Introduction to landscape influences on stream habitats and biological assemblages. Am Fish Soc Symp 2006:1-23

Wang L, Seelbach PW, Lyons J (2006b) Effects of levels of human disturbance on the influence of catchment, riparian, and reach-scale factors on fish assemblages. Am Fish Soc Symp 2006:199-219

Ward JV (1989) The 4-dimensional nature of lotic ecosystems. J N Am Benthol Soc 8:2-8

Zuur AF, Ieno EN, Smith GM (2007) Analysing ecological data. Springer, New York, NY 